$17^{\text {th }}$ International Congress of Metrology, 08010 (2015)

DOI: $10.1051 /$ metrology / 201508010

(C) Owned by the authors, published by EDP Sciences, 2015

\title{
Development of an alternative procedure to verify "in situ" volumetric diaphragm type gas meters for residential use
}

\author{
Alberto J. Díaz Tey. \\ Universidad de Costa Rica. San José de Costa Rica. Centroamérica.
}

\begin{abstract}
Résumé. Cet article montre les performances métrologiques du compteur de gaz portatif mis au point pour les mesures de volume dans le domaine, quand il fonctionne à différentes conditions à l'obtention du diplôme, mais similaires à ceux que vous pouvez trouver au cours périodique "in situ" des inspections de compteurs à gaz de type à diaphragme par NTC 5730: 2009. Les effets de la température des gaz et les positions dans le volume mesuré par portables compteurs de gaz, à des pressions différentes de jauge "en amont" de sa restriction, ont été comparés avec le volume mesuré par mouillé compteur de gaz de la chambre, connectés en série et considéré comme étalon de référence. Le premier facteur (température du gaz) était statistiquement significative (ANOVA $\alpha=5 \%$ ) pour l'air sec, mais pas pour l'azote, cependant, quand désaligné (second facteur), les différences de volumes de gaz était statistiquement significative. La reproductibilité expérimentale de prototype B14, dans la plage de température de $21,0^{\circ} \mathrm{C}$ à $26,0^{\circ} \mathrm{C}$, et pression manométrique de $1742 \mathrm{~Pa}$ à $240 \mathrm{~Pa} 2$, sont: $\pm 0,98 \%$ (azote) et $\pm 1,16 \%$ (air sec) pour un volume d'essai de $21 \mathrm{l}$, ce qui confirme le caractère approprié de l'utilisation de l'azote comme fluide de travail dans le champ. Ces résultats appuient l'utilisation de compteur volumétrique portable en étalon sur le terrain dans la gamme de 4,6 L/min à 5,4 L/min, si examiné les recommandations de ce document.
\end{abstract}

\section{Introduction.}

In mid-2009 a distributor of natural gas in Barranquilla city, Colombia, requested the collaboration to develop an alternative method for verification "in situ" the accuracy of the diaphragm type gas meters for domestic use.

In Colombia, metrological control operations related to the subsequent verification of these measuring instruments are performed through a representative sample of the population installed in a stationary pneumatic bank at different flows, however, is allowed during periodic reviews to facilities for supply of natural gas intended for residential use, the application of an alternative procedure, provided that the requirements of OIML R137-1\&2:2012 [1] are satisfied with respect to the uncertainty of measurement.

From these requirements, a portable gas meter was developed (prototype B14), able to indirectly measure the volume of gas to actual operating conditions, from the test time and volumetric gas flow, adjusted by linear regression to the gauge pressure "upstream" restriction and discharging to atmosphere. Once successfully tested the procedure of graduation [2], and before validating alternative verification procedure "in situ" of diaphragm type gas meter, we proceeded to verify the behavior of portable gas meter outside the range of graduation of influential variables in measuring the gas volume.

As an alternative procedure, its development involved an extensive validation [3], to ensure that the results meet the requirements of reference procedure [1, 4], related to its use as a portable volumetric standard.

For this purpose, were installed in series with the portable volumetric meter, a diaphragm type gas meter, with the function of generating the equivalent pneumatic resistance, and a wet chamber gas meter, which act as a reference standard [3,5].

With the pneumatic circuit ready, were reproduced in the laboratory the conditions that would be encountered during periodic inspections, and its effects were evaluated by designing two experiments nested in three levels:

In the first experimental design, the gas temperature for each operating gauge pressure "upstream" of restriction of portable gas meter (prototype B14), was varied, keeping the rest gas meters aligned.

${ }^{a}$ Auteur de correspondance : teyalb@ice.co.cr 
Its purpose is to evaluate if the volume difference between gas volumes measured, when all gas meter are aligned, is statistically independent of the gas temperature.

In the second experimental design, type diaphragm gas meter was placed in two different positions with respect to wet chamber gas meter, maintained constant gas temperature for each operating gauge pressure "upstream" of restriction of portable gas meter (prototype B14).

Its purpose is to evaluate if the volume difference between gas volumes measured, when gas meter are out of alignment, is statistically independent of its positions.

In both experimental designs, the gas volumes measured by the portable (prototype B14) and the wet chamber gas meters were calculated, adjusted according to its calibration reports but referred to the conditions of gas to $\left(\mathrm{P}_{1}, \mathrm{~T}_{1}\right)$ "upstream" of restriction of portable gas meter (prototype B14).

To evaluate whether the deviation of the corrected gas volume measured by the portable gas meter is significant or not with respect to reference, an Analysis of Variance (ANOVA) to the generated data matrix was applied, after statistically processing [6].

Below are the results, which complement the preliminary study [2], and confirm the use of portable gas meter as a working standard, in the alternative procedure of verifying the accuracy of the diaphragm type gas meter for home use in their periodic review.

\section{Materials and methods.}

\subsection{Portable gas meter.}

The portable gas meter is a measurement system developed for measuring volume of a compressible fluid flowing through a restriction in a given time [2].

Its adjustment equation is defined by equation 1 [2]:

$$
\hat{q}_{v}=\sum_{l=0}^{2} \hat{a}_{l} \times\left(p_{1}\right)^{l}
$$

Where:

$\hat{q}_{v}$ : Volumetric flow to the thermodynamic conditions of gas "upstream" of the restriction during graduation, in $\mathrm{L}$ / $\min$.

$\hat{a}_{l}$ : Least-squares coefficients of the polynomial fit graduation, referred in its calibration certificate (see Table 2).

$p_{1}$ : Gas gauge "upstream" of the restriction, in $\mathrm{inH}_{2} \mathrm{O}$.
Note 1. It is usual for the unit of measurement of gauge pressure refers to the Anglo-American system. Its equivalence in the International System of Units (SI) is 1 $\operatorname{inH}_{2} \mathrm{O}_{\left(60^{\circ} \mathrm{F}\right)}=248,84 \mathrm{~Pa}$ [7].

In Table 1, the thermodynamic parameters of the gas "upstream" of restriction of gas meter are reported.

Table 1. Thermodynamic parameters of gas.

\begin{tabular}{|l|l|l|l|}
\hline $\begin{array}{c}\text { Graduation } \\
\text { date }\end{array}$ & $\begin{array}{c}\text { Operating } \\
\text { fluid }\end{array}$ & $\begin{array}{c}\left(\bar{t}_{1} \pm \Delta t_{1}\right)_{g} \\
{ }^{\circ} \mathrm{C}\end{array}$ & $\begin{array}{c}\left(\bar{P}_{a t} \pm \Delta P_{a t}\right)_{g} \\
\text { in }_{2} \mathrm{O}\end{array}$ \\
\hline $14-04-02$ & Dry air & $24,2 \pm 0,5$ & $406,4 \pm 1,2$ \\
\hline $14-04-15$ & Nitrogen & $24,1 \pm 0,5$ & $407,4 \pm 0,6$ \\
\hline
\end{tabular}

Note 2. The static gauge pressure "upstream" of the restriction of portable gas meter at its graduation varies from $6 \mathrm{inH}_{2} \mathrm{O}$ to $10 \mathrm{inH}_{2} \mathrm{O}$ at intervals of $0,2 \mathrm{inH}_{2} \mathrm{O}$, however, domestic application is in the interval from 7 in $\mathrm{H}_{2} \mathrm{O}$ to $9 \mathrm{inH}_{2} \mathrm{O}$.

The adjustment coefficients for B14 prototype in function of gas operation are reported in Table 2.

Table 2. Adjustment coefficients (B14 prototype).

\begin{tabular}{|c|c|c|c|c|c|}
\hline Símbolo & \multicolumn{2}{|c|}{ Aire seco } & \multicolumn{2}{|c|}{ Nitrógeno } & Unidad de medida \\
\hline$a_{0} \pm s\left(a_{0}\right)$ & 2.067811 & 0.184170 & 2.154920 & 0.160590 & $\mathrm{~L} / \mathrm{min}$ \\
\hline$a_{1} \pm s\left(a_{1}\right)$ & 0.411493 & 0.046780 & 0.385981 & 0.040790 & $(\mathrm{~L} / \mathrm{min}) / \mathrm{inH} 2 \mathrm{O}$ \\
\hline $\mathrm{a}_{2} \pm \mathrm{s}\left(\mathrm{a}_{2}\right)$ & -0.006060 & 0.002920 & -0.003177 & 0.002540 & $(\mathrm{~L} / \mathrm{min}) /(\mathrm{inH} 2 \mathrm{O})^{\wedge} 2$ \\
\hline
\end{tabular}

Where:

$s\left(a_{l}\right)$ : Standard deviation of the minimum-square estimate of the adjustment coefficients.

\subsection{Reference standard gas meter.}

As standard reference an wet chamber gas meter was used, with the following metrological characteristics:

Table 3. Wet chamber gas meter: metrological characteristics.

\begin{tabular}{|c|c|c|c|}
\hline $\begin{array}{l}\text { Value of division / } \\
\text { Appreciation }\end{array}$ & \multicolumn{2}{|c|}{$\begin{array}{l}\text { Measurement interval, } \\
(\mathrm{L} / \mathrm{min})\end{array}$} & a) $\mathrm{MPE}$ \\
\hline \multirow[t]{3}{*}{$10 \mathrm{~mL} / 1 / 2$} & 0,2 & $<2$ & $\pm 1 \%$ \\
\hline & $\geq 2$ & $\leq 6$ & $\pm 0,5 \%$ \\
\hline & $>6$ & $\leq 8$ & $\pm 1 \%$ \\
\hline
\end{tabular}

${ }^{a)}$ Maximum permissible error.

The reference standard gas meter was calibrated twice in the Carl Poe Laboratory, using as a reference standard a volumetric bell American Bell Prover s/n 277. Its maximum drift is reported in Table 4. 


\section{$17^{\text {th }}$ International Congress of Metrology}

Table 4. Maximum drift of relative error by volume of reference standard gas meter.

\begin{tabular}{|l|l|c|}
\hline Graduation Date & Traceability & $\begin{array}{c}\text { Maximum drift } \\
\left(\Delta e r_{d e r}^{M A X}\right)\end{array}$ \\
\hline $2011-05-10$ & NIST 12169734 & $0,071 \% /$ año \\
\hline $2014-03-06$ & NIST 11200311 & \\
\hline
\end{tabular}

Currently the period assigned between external calibration is two years.

\subsection{Chronometer.}

A digital chronometer was used with the following metrological characteristics to measure testing time:

Table 5. Metrological characteristics of digital chronometer.

\begin{tabular}{|l|l|l|}
\hline Measurement interval: to & Resolution & MPE \\
\hline 9 h $59 \min 59$ s 99 cs & $1 \mathrm{cs}$ & $\pm 0,002 \%$ \\
\hline
\end{tabular}

The digital chronometer is calibrated annually by comparison with a pulse counter of a sinusoidal signal generated by a controllable source of high accuracy.

\subsection{Diaphragm type gas meter.}

The diaphragm type gas meter was installed in series between the reference standard gas meter and portable gas meter, so, with its pneumatic load, emulate real field situation.

Although the quality of volume measurements of diaphragm type gas meter are not relevant to the present study, its metrological characteristics correspond to those of a volumetric meter 1.6 [8].

\subsection{Pneumatic installations.}

To perform the first experimental design, a pneumatic bench was constructed, were all gas meters are aligned and installed in series, and portable gas meter always discharging to atmosphere, as shown in Figure 1.

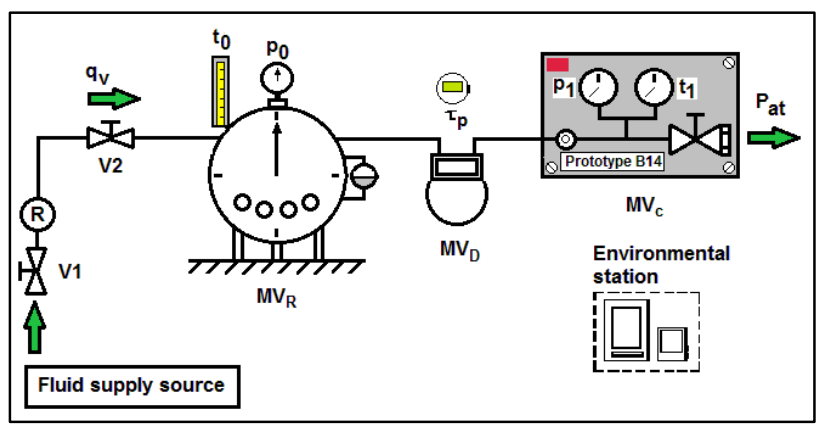

Figure 1. Simplified diagram of first experimental design.
Where:

V1: Open / close valve.

(R): Pressure regulator.

V2: Fine regulator valve.

$\mathrm{MV}_{\mathrm{R}}$ : Reference standard gas meter.

$\mathrm{p}_{0}$ and $\mathrm{t}_{0}$ : Manometer and thermometer of reference standard gas meter.

$\tau_{\mathrm{p}}$ : Chronometer.

$M V_{D}$ : Diaphragm type gas meter.

$\mathrm{MV}_{\mathrm{c}}$ : Portable gas meter.

$\mathrm{p}_{1}$ and $\mathrm{t}_{1}$ : Manometer and thermometer of portable gas meter.

$\mathrm{P}_{\mathrm{at}}$ : Atmospheric discharge.

To perform the second experimental design, which considers different positions of diaphragm type gas meter with respect to reference standard gas meter, the following installations were designed:

First scheme: the type diaphragm gas meter is aligned to portable gas meter but located in lower position with respect to the reference standard gas meter (see Figure 2).

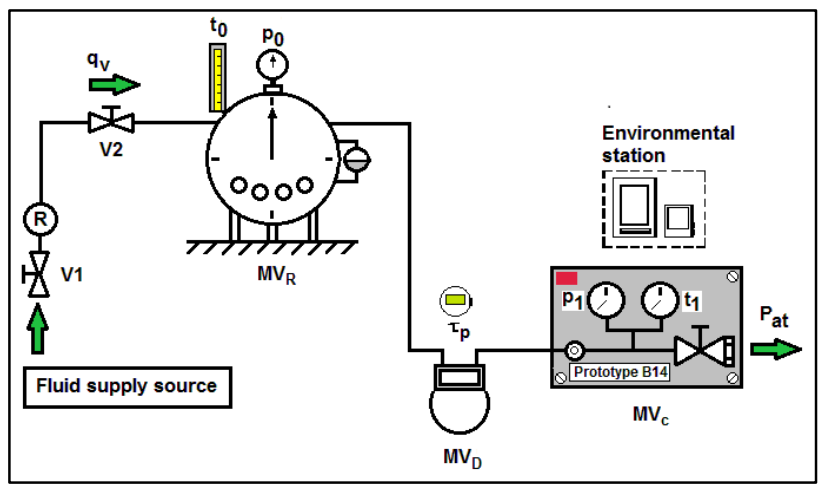

Figure 2. Simplified diagram of the first scheme.

Second scheme: the type diaphragm gas meter is in upper position relative to the portable and reference standard gas meters, aligned with each other (see Figure 3 ).

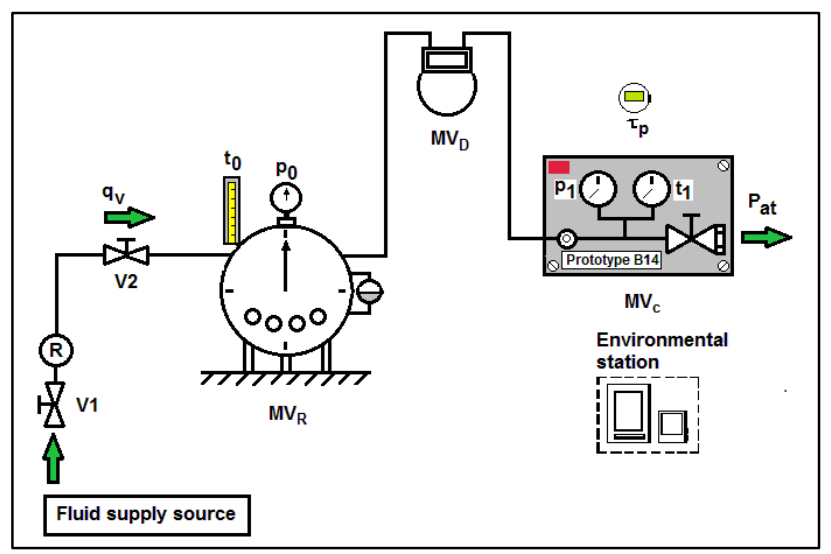


Figure 3. Simplified diagram of the second scheme.

Note 3. The main functions and characteristics of the components of the measuring system referred in Figures 1,2 and 3 can be consulted at [2].

\subsection{Corrected volume of gas.}

\subsubsection{Portable gas meter.}

The gas volume measured by the portable gas meter is defined by Equation 2 .

$$
V_{c m}=\tau_{p} \times \hat{q}_{v}=\tau_{p} \times \sum_{l=0}^{2} \hat{a}_{l} \times\left(p_{1}\right)^{l}
$$

Where:

$V_{c m}$ : Measured volume of gas, depending on the fitting equation (see equation 1 ), in $\mathrm{L}$.

$\tau_{p}$ : Test time measured by the chronometer, in min.

Note 4. The test time is the delay in reaching diaphragm type gas meter cumulative volume of $21 \mathrm{~L}$.

The volume corrected but referred to gas conditions at graduation portable gas meter, it is calculated according to equation 3 .

$$
V_{c g}=V_{c m} \times\left(1+0,01 \times e_{c r}\right)^{-1}
$$

Where:

$V_{c g}$ : Volume corrected but referred to gas conditions $\left(P_{g}, T_{g}\right)$ during its graduation, based on its calibration certificate, in $\mathrm{L}$.

$e_{c r}$ : Relative error by volume, based on its calibration certificate depending on the volumetric flow, in $\%$.

\subsubsection{Reference standard gas meter.}

The gas volume measured by the reference standard gas meter is calculated according to equation 4 .

$$
V_{p 0}=\frac{V_{p m}}{1+0,01 \times\left(e r_{R}+\Delta e r_{d e r}\right)}
$$

Where:

$V_{p 0}$ : Corrected volume based on gas conditions $\left(P_{0}, T_{0}\right)$, in L.

$V_{p m}$ : Gas volume measured by the reference standard meter, from the final and initial volumes of test, in L.

$e_{p r}$ : Relative error in volume, based on its calibration certificate according to the volumetric flow, in $\%$.

$\Delta e_{d e r}$ : Drift correction of relative error in volume, in $\%$. Its mathematical expectation is zero but contributes to measurement`s uncertainty [9].

\subsection{Corrected volume and referred to the gas conditions $\left(\mathbf{P}_{1}, \mathbf{T}_{1}\right)$.}

As the operating gas pressure is too low ( $p_{1 \text { max }} \leq$ $9,0 \mathrm{inH}_{2} \mathrm{O}$ ), the calibration occurs practically at atmospheric pressure, therefore, can be considered acceptable that the effect of the compressibility factor of the gas behavior is negligible, that is, $Z=1,000$ [10].

Under these circumstances, the gas can be treated as ideal, and for comparing the measured volumes of gas in different thermodynamic states, the Clapeyron equation is used [10], which in its general form is defined by equation 5 .

$$
V_{1}=V_{0} \times F C P \times F C T
$$

Where:

FCP and FCT: Correction factors for pressure and temperature respectively, dimensionless.

Note 5. The subscripts 0 and 1 refer to the thermodynamic conditions of gas initial and final from the point of view of measurement.

The pressure correction factor is calculated according to equation 6.

$$
F C P=\frac{P_{0}}{P_{1}}=\frac{\left(p+P_{a t}\right)_{0}}{\left(p+P_{a t}\right)_{1}}
$$

Where:

$P$ y $p$ : Absolute and gage static gas pressure respectively, in in $\mathrm{H}_{2} \mathrm{O}$.

$P_{a t}:$ Atmospheric pressure, in $\mathrm{inH}_{2} \mathrm{O}$.

The temperature correction factor is calculated according to equation 7 .

$$
F C T=\frac{T_{1}}{T_{0}}=\frac{(273,15+t)_{1}}{(273,15+t)_{0}}
$$

Where:

$T$ and $t$ : Thermodynamic and Celsius gas temperatures, in $\mathrm{K}$ and ${ }^{\circ} \mathrm{C}$ respectively.

\subsubsection{Portable gas meter.}

In the case of portable gas meter, equation 5 takes the following form:

$$
V_{c 1}=V_{c g} \times F C P_{c} \times F C T_{c}
$$

Where:

$V_{c 1}$ : Volume corrected to gas conditions $\left(P_{1}, T_{1}\right)$ during its operation, in L. 


\section{$17^{\text {th }}$ International Congress of Metrology}

For the pressure correction factor, equation 6 takes the form:

$$
F C P_{c}=\frac{P_{g}}{P_{1}}=\frac{\left(p+P_{a t}\right)_{g}}{\left(p+P_{a t}\right)_{1}}
$$

For the temperature correction factor, equation 7 takes the form:

$$
F C T_{c}=\frac{T_{1}}{T_{0}}=\frac{(273,15+t)_{1}}{(273,15+t)_{g}}
$$

\subsubsection{Reference standard gas meter.}

In the case of reference standard gas meter, equation 5 takes the following form:

$$
V_{p 1}=V_{p 0} \times F C P_{p} \times F C T_{p}
$$

Where:

$V_{p 1}$ : Volume corrected at gas conditions $\left(P_{1}, T_{1}\right)$ "upstream" the restriction of portable gas meter, in L.

For the pressure correction factor, equation 6 takes the form:

$$
F C P_{p}=\frac{P_{0}}{P_{1}}=\frac{\left(p+P_{a t}\right)_{0}}{\left(p+P_{a t}\right)_{1}}
$$

For the temperature correction factor, equation 7 takes the form:

$$
F C T_{p}=\frac{T_{1}}{T_{0}}=\frac{(273,15+t)_{1}}{(273,15+t)_{0}}
$$

\subsection{Difference of corrected volumes relating to gas conditions $\left(\mathbf{P}_{1}, \mathbf{T}_{1}\right)$.}

The difference of corrected volumes relating to conditions gas $\left(\mathrm{P}_{1}, \mathrm{~T}_{1}\right)$, hereinafter referred simply as volume difference, is defined by equation 8 .

$$
\Delta V_{c 1}=V_{c 1}-V_{\mathrm{p} 1}
$$

Where:

$\Delta V_{c 1}$ : Volume difference, in $\mathrm{mL}$.

\subsection{Precision estimate of difference of corrected volumes.}

To evaluate the precision of volumes difference of portable gas meter, B14 prototype was constructed and an experiment was designed compensated for nested three levels of operation for each gas (dry air and nitrogen) [6]:

Level 1. Gauge pressure "upstream" of the restriction $(i$ $=1 ; 2 ; \ldots p=3$ ).
Level 2-1. Gas temperature "upstream" of the restriction portable gas meter (experimental design 1).

Level 2-2. Relative position of the diaphragm type gas meter relative to reference standard gas meter (experimental design 2).

In general, for Level $2: j=1 ; 2 ; q=3$.

Level 3. Results of measurements of corrected volume of gas $(k=1 ; 2 ; n=3)$.

The continuous random variable analyzed (volume difference) is represented as $\left(\Delta V_{c 1}\right)_{i j k}$.

For evaluating the effect "relative position" (level 2 of the experimental design 2), the operation gas temperature remained approximately constant (see Table 6.2).

\subsection{Processing measurements.}

Measurements of the output variable (difference volumes) are arranged in matrix form and the compliance with the following theoretical assumptions is evaluated:

$\checkmark$ The agreement of the experimental distribution of the measured variable $\Delta V_{c 1}$ with normal probability distribution proposed.

$\checkmark$ The homogeneity of variances of the series of measurements $\Delta V_{c 1}$ (homoscedasticity) according to Bartlett test [11].

If the above assumptions are met, statistically evaluate incompatible values (outliers) consecutively applying the Cochran and Grubbs tests [6].

If the presence of an "outlier" is confirmed, the causes that originate are analyzed and corrective and / or preventive actions are taken, as the case.

To evaluate the effect of each of the factors mentioned and their statistical interaction, ANOVA was applied [6].

Depending on the results of ANOVA are reported for interest in this study, the following estimates of the volumes difference [6]:

- Large average $\left(\overline{\overline{\Delta V}}_{c 1}\right)$.

- Repeatability standard deviation $\left[s_{r}\left(\Delta V_{c 1}\right)\right]$.

- Reproducibility standard deviation $\left[s_{R}\left(\Delta V_{c 1}\right)\right]$.

\section{Results.}

The measurements were performed in Barranquilla, Colombia, from April 24 to May 13, 2014. The average environmental behavior in the period is referred in Tables 6.1 and 6.2 . 
Table 6.1. Ambient conditions (experimental design 1).

\begin{tabular}{|l|c|c|c|}
\hline & $t_{a} \pm \Delta t_{a}$ & $H R \pm \Delta H R$ & $P_{a t} \pm \Delta P_{a t}$ \\
\hline Gas & ${ }^{\circ} \mathrm{C}$ & $\%$ & $\mathrm{hPa}$ \\
\hline Air & $23,7 \pm 5,0$ & $48,6 \pm 9,8$ & $1011,7 \pm 1,0$ \\
\hline Nitrogen & $23,8 \pm 5,0$ & $49,3 \pm 10,0$ & $1012,2 \pm 0,6$ \\
\hline
\end{tabular}

Table 6.2. Ambient condintios (experimental design 2).

\begin{tabular}{|l|c:c:c|}
\hline & $t_{a} \pm \Delta t_{a}$ & $H R \pm \Delta H R$ & $P_{a t} \pm \Delta P_{a t}$ \\
\hline Gas & ${ }^{\circ} \mathrm{C}$ & $\%$ & $\mathrm{hPa}$ \\
\hline Dry air & $23,8 \pm 0,4$ & $45,0 \pm 1,4$ & $1013,0 \pm 0,0$ \\
\hline Nitrogen & $24,3 \pm 0,6$ & $49,5 \pm 1,4$ & $1012,5 \pm 0,0$ \\
\hline
\end{tabular}

Once the matrices of the output variable for each experimental design, statistical tests passed successfully applied consecutively, without any value statistically incompatible detected, the ANOVA was applied with a significance level $\alpha=5 \%$. ANOVA results for the experimental designs 1 and 2 are reported in Tables 7.1 and 7.2 respectively.

Table 7.1. Experimental design 1: results of ANOVA ( $\alpha=$ $5 \%$ ) for operating fluid.

\begin{tabular}{|l|c|c|c|c|c|}
\hline & Dry air & Nitrogen & \multicolumn{3}{|c|}{ Critical statistical } \\
\hline Source & $F_{c}$ & $F_{c}$ & $v_{1}$ & $v_{2}$ & $F_{(1-\alpha)}\left(v_{1}, v_{2}\right)$ \\
\hline $\begin{array}{c}\text { Factor } 0 \\
\left(p_{1}\right)\end{array}$ & 0,04 & 1,18 & 2 & 3 & 5,14 \\
\hline $\begin{array}{c}\text { Factor } 1 \\
\left(t_{1}\right)\end{array}$ & 5,28 & 0,55 & & & 4,76 \\
\hline
\end{tabular}

Table 7.2. Experimental design 2: results of ANOVA $(\alpha=$ $5 \%$ ) for operating fluid.

\begin{tabular}{|l|c|c|c|c|c|}
\hline & Dry air & Nitrogen & \multicolumn{3}{|c|}{ Critical statistical } \\
\hline Source & $F_{c}$ & $F_{c}$ & $v_{1}$ & $v_{2}$ & $F_{(1-\alpha)}\left(v_{1}, v_{2}\right)$ \\
\hline $\begin{array}{c}\text { Factor 0 } \\
\left(p_{1}\right)\end{array}$ & 1,50 & 0,10 & 2 & 3 & 5,14 \\
\hline $\begin{array}{c}\text { Factor 1 } \\
(\Delta H)\end{array}$ & 10,13 & 28,31 & & & 4,76 \\
\hline
\end{tabular}

Where:

$v_{1}=p-1$ and $v_{2}=p$ : Degrees of freedom.

Tables 8 refers pooled parameters that define the volume difference precision for the experimental designs 1 and 2 .
Table 8.1. Experimental design 1: volume difference precision, in $\mathrm{mL}$.

\begin{tabular}{|l|c|c|c|}
\hline Gas & a) $\overline{\overline{\Delta V}}_{c 1}$ & a) $s_{r}\left(\Delta V_{c 1}\right)$ & ${ }^{\text {a) }} s_{R}\left(\Delta V_{c 1}\right)$ \\
\hline Dry air & $\begin{array}{c}-91 \\
(-0,43 \%)\end{array}$ & $\begin{array}{c}90 \\
(0,43 \%)\end{array}$ & $\begin{array}{c}244 \\
(1,16 \%)\end{array}$ \\
\hline Nitrogen & $\begin{array}{c}-31 \\
(-0,15 \%)\end{array}$ & $\begin{array}{c}106 \\
(0,51 \%)\end{array}$ & $\begin{array}{c}206 \\
(0,98 \%)\end{array}$ \\
\hline
\end{tabular}

Table 8.2. Experimental design 2: volume difference precision, in $\mathrm{mL}$.

\begin{tabular}{|l|c|c|c|}
\hline Gas & a) $\overline{\Delta V}_{c 1}$ & ${ }^{\text {a) }} s_{r}\left(\Delta V_{c 1}\right)$ & ${ }^{\text {a) }} s_{R}\left(\Delta V_{c 1}\right)$ \\
\hline Dry air & $\begin{array}{c}98 \\
(0,47 \%)\end{array}$ & $\begin{array}{c}89 \\
(-0,42 \%)\end{array}$ & $\begin{array}{c}329 \\
(1,56 \%)\end{array}$ \\
\hline Nitrogen & $\begin{array}{c}304 \\
(1,45 \%)\end{array}$ & $\begin{array}{c}163 \\
(0,78 \%)\end{array}$ & $\begin{array}{c}898 \\
(4,28 \%)\end{array}$ \\
\hline
\end{tabular}

a) Percentage $(\%)$ referred to $21 \mathrm{~L}$.

In the compendium of figures numbered as Figure 4 are shown, using Sheward control chart as a statistical tool [12], the metrological performances of the B14 prototype portable gas meter, in function of the volumes difference for experimental design 1 and operating gas.

Note 6. The procedure for establishing the control limits: Limits Warning (LA - - ) and Limits of Action (LC - - ) of the output variable evaluated are referred in Section 3 of [12].

Within the limits of Upper Warning (LAS) and Lower (LAI) [12], is expected that the results of any future calculation of the volumes difference are, whenever it takes place in the period assigned between external calibrations reference standard gas meter used (see Tables 2 and 3$)$.

If reference standard gas meter drift is higher than expected, it is likely that the new results are in the band between the warning limits (LA) and action (LC) [12]; in this case, the calibration laboratory should review the assigned period between external calibrations of standard gas meter used.

The metrological performance of portable gas meter developed (prototype B14) when gas temperatures are different from graduation, but all gas meters are aligned, is shown in Figures 4. 


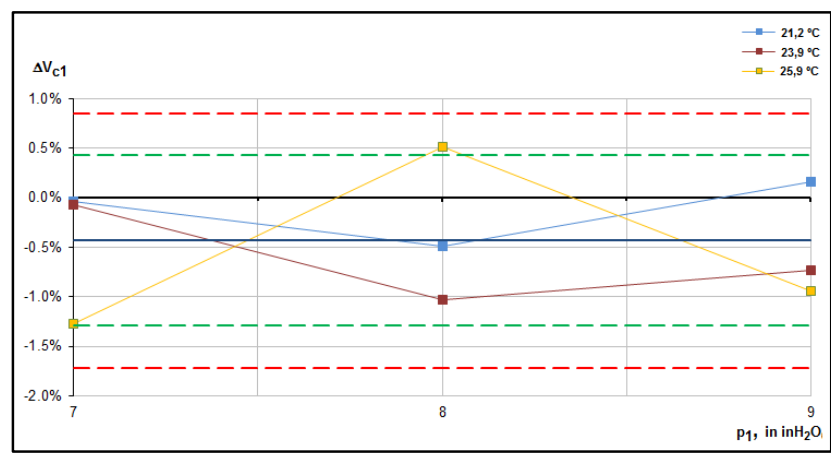

Fig. 4.1. Statistical limits of repeatability: dry air.

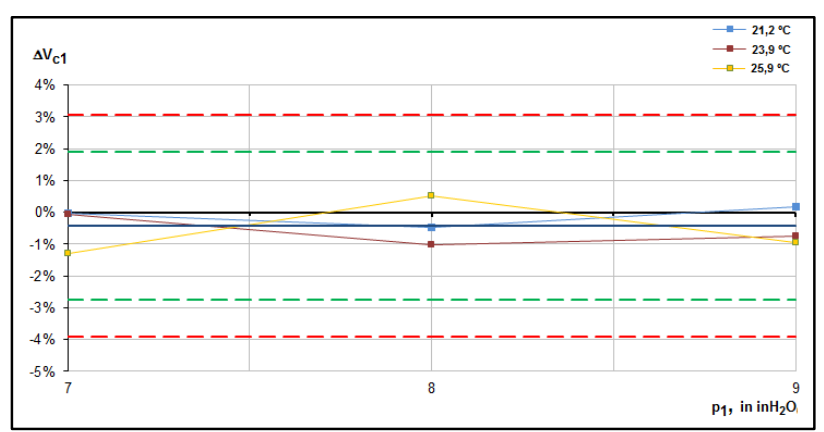

Fig. 4.2. Statistical limits of reproducibility: dry air.

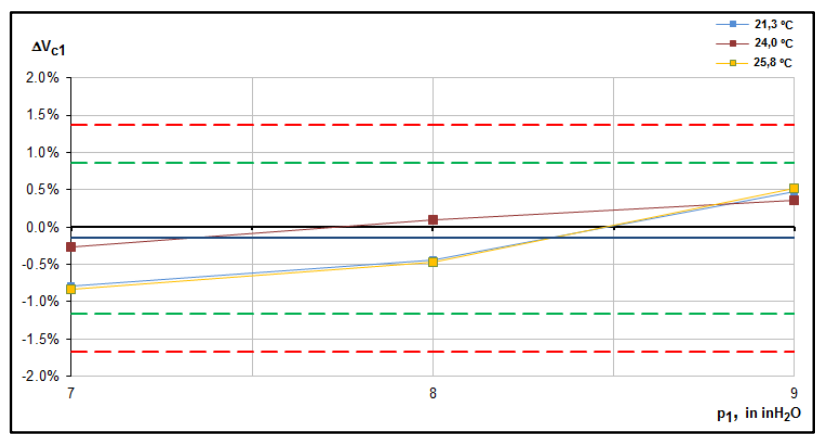

Fig. 4.3. Statistical limits of repeatability: nitrogen.

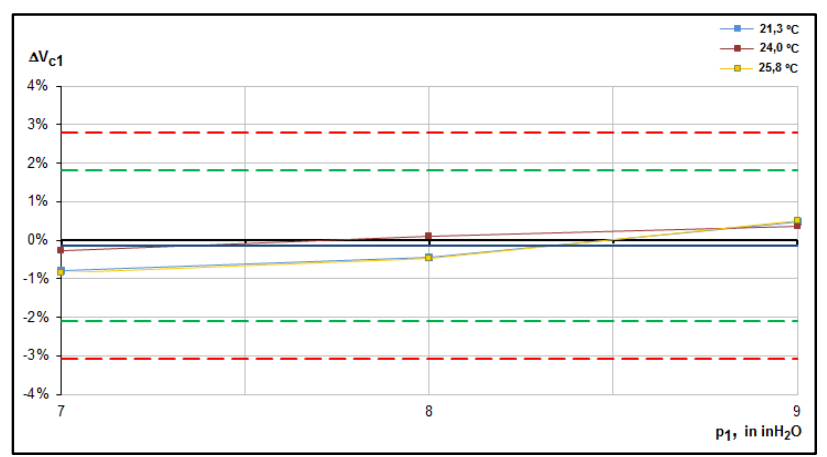

Fig. 4.4. Statistical limits of reproducibility: nitrogen.

\section{Discussion.}

For the experimental design 1, ANOVA results for $\alpha=$ $5 \%$ (see Table 7.1 ) confirm that the effects of static gauge pressure "upstream" restriction of portable gas meter are not statistically significant for volume difference in both: dry air and nitrogen.

In the case of gas temperature, ANOVA results for $\alpha=$ $5 \%$ (see Table 7.1) confirm that its effects is not statistically significant for volume difference in nitrogen but it is significant for dry air.

In the case of experimental design 2, ANOVA results for $\alpha=5 \%$ (see Table 7.2) confirm that effects of relative position of diaphragm type meter for each reproduced gauge pressure is statistically significant in volume difference for both dry air and nitrogen.

In Table 9 are reported differences of repeatability obtained during graduation [2] of portable gas meter with respect to operating conditions (aligned).

Table 9. Differences of repeatability obtained.

\begin{tabular}{|l|c|c|c|c|}
\hline & \multicolumn{2}{|c|}{${ }^{\text {a) }}$ At graduation } & \multicolumn{2}{c|}{ a) In field } \\
\hline Gas & $s_{r}\left(\mathrm{er}_{V}\right)$ & $s_{R}\left(\mathrm{er}_{V}\right)$ & $s_{r}\left(\Delta V_{c 1}\right)$ & $s_{R}\left(\Delta V_{c 1}\right)$ \\
\hline \multirow{2}{*}{ Dry air } & $3 \mathrm{~mL}$ & $3 \mathrm{~mL}$ & $90 \mathrm{~mL}$ & $244 \mathrm{~mL}$ \\
& $(0,014 \%)$ & $(0,014 \%)$ & $(0,43 \%)$ & $(1,16 \%)$ \\
\hline \multirow{2}{*}{ Nitrogen } & $5 \mathrm{~mL}$ & $5 \mathrm{~mL}$ & $106 \mathrm{~mL}$ & $206 \mathrm{~mL}$ \\
& $(0,023 \%)$ & $(0,023 \%)$ & $(0,51 \%)$ & $(0,98 \%)$ \\
\hline
\end{tabular}

a) Percentage (\%) referred to $21 \mathrm{~L}$.

Although the variables are obtained by different methods, the comparison is valid because both express deviations from the same reference: gas volume corrected to $\left(\mathrm{P}_{1}, \mathrm{~T}_{1}\right)$ measured by the same reference standard gas meter.

It was expected that under conditions of graduation, the repeatability standard deviations were lower, however, the values obtained are still less than $1 \%$ required by the NTC 5730: 2009 [4].

Why not use the values of reproducibility? Because not apply for a simple verification in field of diaphragm type gas meter. This process happens, by the nature of the test, under conditions of repeatability, whose pooled values represent the maximum experimental variation obtained.

When reproducibility values be used? In the comparison of the results of different tests of the same type diaphragm gas meter. For example, if the gas meter is sent to a calibration laboratory for verification by the process reference [5].

\section{Conclusions and recommendations.}

Considering the temperature effect on volume difference when the operating fluid is dry air (see ANOVA Table 6.1 ), it is more important to control the temperature 
variations of air supply that its value, when using the portable gas meter as volumetric field standard.

However, conditioning and control not only the temperature but also humidity, in verifying the diaphragm type gas meter, are complex and expensive technological operations when performed in field.

Although not expected, by the nature of the fluid and small height differences $(\Delta \mathrm{H}<1,5 \mathrm{~m})$, the effect of the relative position of the diaphragm type gas meter was significant in volumes difference, experimental results demonstrated the opposite: it is statistically significant $(\alpha$ $=5 \%$ ) regardless of the nature of the gas (see Table 6.2 ANOVA).

However, its effect is significantly superior in nitrogen $\left(\mathrm{F}_{\mathrm{c}}=28,31\right)$ than dry air $\left(\mathrm{F}_{\mathrm{c}}=10,13\right)$.

This study complements the validation of graduation procedure of portable gas meter [2], and its results confirm the robustness of its metrological performance to the influential variables that are present in the field during verification of diaphragm type gas meter.

It is recommended:

1R. Using industrial grade nitrogen as operation gas. It was shown from the validation of graduation procedure of portable gas meter [2], its advantages over the "dry air":

$\checkmark$ The portable power supply is much simpler: a cylinder with a high pressure regulator is sufficient.

$\checkmark$ Its high purity and composition stability is ensured by the Provider.

$\checkmark$ Generates better reproducibility in metrological performance of portable gas meter: $206 \mathrm{~mL}$ versus 244 $\mathrm{mL} ¡ 18 \%$ better! (see Tables 7).

2R. When performing inspections "in situ" of diaphragm gas meters type according to NTC 5730: 2009 standard [4], keep aligned portable gas meter that acting as field standard, especially if nitrogen is used as working fluid.

3R. Use the OIML criterion [1] if the expanded uncertainty of the calibration of the diaphragm type gas meter is greater than $1 \%$.

4R. Extend the study to other regions, for example higher or colder than Barranquilla city.

5R. Evaluate the technical advantages of digitizing temperature and gauge pressure measurements of gas operation with respect to higher prices of portable gas meter.

6R. Develop an alternative method to direct measurement of atmospheric pressure with a barometer.

Acknowledgements.

The author appreciated the valuable collaboration provided by the Caribbean Gas and Zambrano Group in the metrological solution presented.

\section{References}

1. OIML R137-1\&2. Gas meter. Part 1: Metrological and technical requirements. Part 2: Metrological controls and performance tests. Edition 2012 (E).

(http://www.oiml.org/publications)

2. Díaz Tey, Alberto J., Rojas Millán, Rafael. Validación del desempeño metrológico. Medidor volumétrico portátil para verificar "in situ" a los medidores de gas tipo diafragma de uso

(http://www.cdtdegas.com/descargas/Edicion\%209/Revista\%20ME T\&FLU\%209.pdf)

3. OIML V 2-200. Edition 2012 (E/F) (JCGM 200:2012). International vocabulary of metrology - Basic and general concepts and associated terms (VIM). 3rd edition 2008 version with minor corrections. (http://www.oiml.org/publications/V/V002-200-e12.pdf)

4. NTC 5730:2009. Revisión periódica de instalaciones para suministro de gas natural destinadas a usos residenciales y comerciales y sus correspondientes artefactos a gas. 2009-12-16.

5. ISO/IEC 17025:2005 (E). General requirements for the competence of testing and calibration laboratories. Second edition. 2005.

6. ISO 5725-3:1994. Accuracy (trueness and precision) of measurement methods and results. Part 3: Intermediate measures of the precision of a standard measurement method.

7. NIST Special Publication 811.Guide for the Use of the International System of Units (SI). 2008 Edition (http://www.bipm.org/en/si/conversions.html)

8. NTC 2728. Medidores de gas tipo diafragma. Primera actualización. 2005.

9. OIML G1-100 Edition 2008 (E)) (JCGM 100:2008). GUM 1995 with minor corrections. Evaluation of measurement data - Guide to the expression of uncertainty in measurement. First edition September 2008. 134 pages (http://www.oiml.org/publications).

10. Dietrich, Harald, "et al". Measuring instruments for gas. Gas Meter Testing of Gas Volume Meters whit Air at Atmospheric Pressure. PTB Testing Instructions. Volume 29. 2003.

11. Engineering Statistics Handbook (http://www.itl.nist.gov/div898/handbook.htm)

12. ISO 3534-2: 1993 (E/F). Statistics - Vocabulary and symbols. Part 2: Statistical quality control. First edition. 1993-06-01. 